\title{
Subamniotic Haematoma Associated with an Uneventful Labour
}

"Nabil Abdalla, Robert Piorkowski, Pawel Stanirowski, Krzysztof Cendrowski, Wlodzimierz Sawicki

$$
\text { ورم دموي تحت السلوي مرتبط بولادة خالية من الأحداث }
$$

نبيل عبد الله، روبرت بيوركواسكي، بأول ستانيرويسكي، كريزستوف سيندوسكرسي، لودزميرز ساويكي
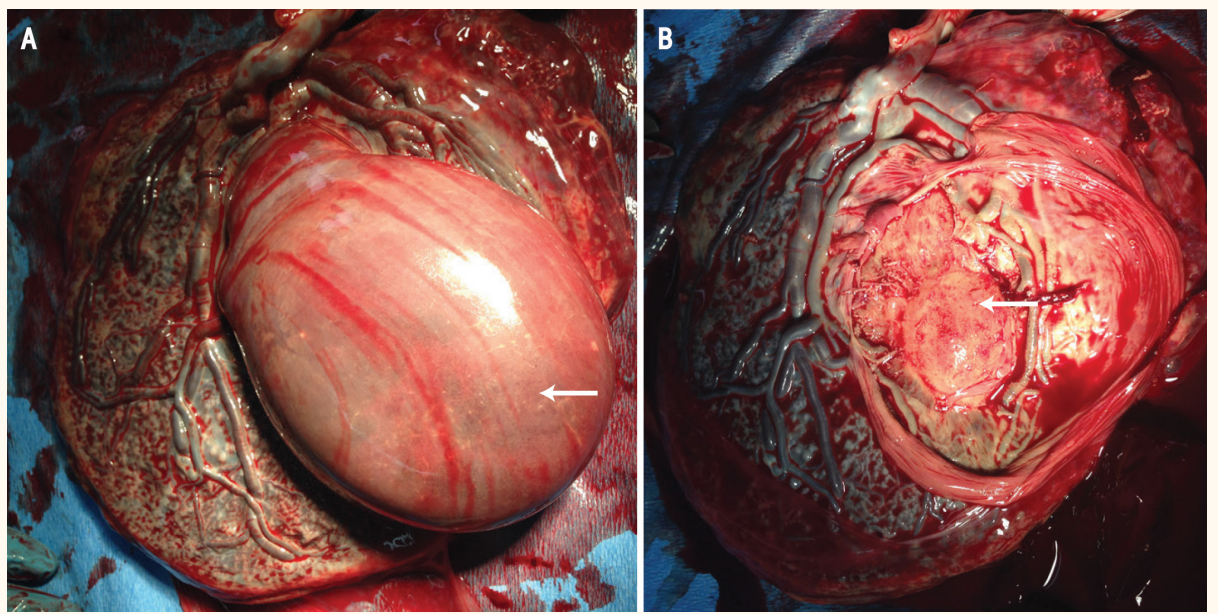

Figure 1: Photographs showing (A) a subamniotic haematoma (arrow) and (B) an ischaemic infarction (arrow) in the placenta of a 34-year-old Caucasian multiparous woman following an uneventful labour at 40 gestational weeks.

A

34-Year-old CaUCASian multiparous woman (gravida 3, para 1) in labour was admitted to the Department of Obstetrics, Gynecology \& Oncology, Medical University of Warsaw, Poland, in 2016 at 40 gestational weeks and three days. Her pregnancy had been uneventful, aside from the development of gestational diabetes, which was controlled by dietary changes. An ultrasonogram showed a fundal placenta with no abnormalities. The membranes ruptured spontaneously 50 minutes after admission. The first and second stages of labour lasted for 9 hours and 40 minutes, respectively. Cardiotocography monitoring did not show any abnormalities.

The fetal head was delivered in the occiput posterior position. The infant's Apgar scores were 9, 9 and 10 at the first, third and fifth minutes, respectively. At birth, the baby weighed 4,280 g. Active management of the third stage of labour was undertaken and the placenta was delivered 5 minutes later by controlled cord traction. The placenta measured 19 x $18 \mathrm{~cm}$.
A macroscopic inspection showed a subamniotic haematoma measuring $15 \times 8 \times 7 \mathrm{~cm}$ located between the amnion and chorionic plate [Figure 1A]. After rupturing the haematoma, a pale area of $6 \times 5 \mathrm{~cm}$ in size could be observed at the base of the haematoma [Figure 1B]. The umbilical cord had three blood vessels. A microscopic histopathological examination showed an ischaemic infarction in the observed pale area. No other abnormalities were noted in the placenta, amniotic membranes or umbilical cord.

The first three days of the puerperal period were uneventful. The results of a maternal full blood count on the second day following delivery indicated a haemoglobin level of $10.6 \mathrm{~g} / \mathrm{dL}$ and red blood cell (RBC) count of $3.64 \times 10^{6} / \mu \mathrm{L}$. An echocardiogram and cranial and abdominal ultrasounds of the neonate were normal. On the third day, the blood tests showed a haemoglobin level of $16.7 \mathrm{~g} / \mathrm{dL}$ and RBC count of 4.78 $\mathrm{x} 10^{6} / \mu \mathrm{L}$. Both the mother and baby were subsequently discharged in good condition later that day. 


\section{Comment}

Placental haematomas can be anatomically classified into three main types: subchorionic, retroplacental and subamniotic. ${ }^{1}$ The origin of blood in retroplacental and subchorionic haematomas is maternal. However, subamniotic placental haematomas are rare and result from the rupture of chorionic vessels near the umbilical cord insertion; most of these types of haematomas are discovered after birth and result from excessive traction of the umbilical cord. ${ }^{1,2}$ However, some may occur during pregnancy, with Van Den Bosch et al. previously reporting an antenatal subamniotic haematoma diagnosed at 34 gestational weeks and associated with an uneventful pregnancy and labour. ${ }^{3}$

In the current case, the precise moment of formation of the haematoma could not be established. It may have developed during labour or due to excessive traction of the umbilical cord. However, as the bleeding arose from the allantochorionic vessels and surprisingly had no effect on the fetus and the course of labour was uneventful, this may suggest that the haematoma was formed during the third stage of labour. The presence of both a placental infarction and subamniotic haematoma is rather coincidental, as a placental infarction that results from the arrest of maternal intervillous blood flow from the uteroplacental spinal arteries cannot be related to the rupture of a chorionic vessel. ${ }^{2}$ As such, the placenta in the present case was sent for histopathological examination to assess the solid mass of the placenta and to exclude rare placental neoplasms, such as a chorioangioma. ${ }^{4}$ Placental infarctions may also be related to gestational diabetes. ${ }^{5}$

\section{References}

1. Loi K, Tan KT. Massive pre-placental and subchorionic haematoma. Singapore Med J 2006; 47:1084-6.

2. Deans A, Jauniaux E. Prenatal diagnosis and outcome of subamniotic hematomas. Ultrasound Obstet Gynecol 1998; 11:319-23. doi: 10.1046/j.1469-0705.1998.11050319.x.

3. Van Den Bosch T, Van Schoubroeck D, Cornelis A, Dubin M. Prenatal diagnosis of a subamniotic hematoma. Fetal Diagn Ther 2000; 15:32-5. doi: 10.1159/000020971

4. Abdalla N, Bachanek M, Trojanowski S, Cendrowski K, Sawicki W. Placental tumor (chorioangioma) as a cause of polyhydramnios: A case report. Int J Womens Health 2014; 6:955-9. doi: 10.2147/IJWH.S72178

5. Salge AK, Rocha KM, Xavier RM, Ramalho WS, Rocha ÉL, Guimarães JV, et al. Macroscopic placental changes associated with fetal and maternal events in diabetes mellitus. Clinics (Sao Paulo) 2012; 67:1203-8. doi: 10.6061/clinics/2012(10)13. 